\title{
OS GÊNEROS Rigidoporus MURR. E Flaviporus MURR. (BASICIOMYCETES) NO PARQUE NACIONAL DE APARADOS DA SERRA, RS
}

\author{
Rosa Mara B. da Silveira(1) \\ Rosa T. Guerrero(1)
}

RESUMO - Como parte do levantamento dos fungos xilófagos poliporóides da mata de Araucaria do Parque Nacional de Aparados da Serra - RS, apresenta-se neste trabalho o estudo dos representantes de dois gêneros estreitamente relacionados, Rigidoporus e Flaviporus. Do gênero Rigidoporus foram identificados três espécies: $R$. lineatus (Pers.) Ryv, $R$. ulmarius (Sow. ex Fr.) Imazeki, $R$. umbonatipes Rajch., esta última constitui citação nova para o Brasil. O gênero Flaviporus também está representado por três espécies: $F$. subhydrophilus (Speg.) Rajch \& Wright, $F$. venustus David \& Rajch e Flaviporus sp. São apresentadas chaves para a identificação, descrições, comentários e ilustraçōes das espécies estudadas.

Palavras-chave: Rigidoporus, flaviporus, Sistemática, Basidiomycetes.

\begin{abstract}
The genera Rigidoporus Murr. and Flaviporus Murr. (Basidiomycetes) from Aparados da Serra National Park, RS).

This work is part of the survey about polyporoids xylophagous fungi from the Araucaria wood of the Aparados da Serra Nacional Park. RS. It includes the species of two closely related genera Rigidoporus and Flaviporus that occur in this area. The genera Rigidoporus is represented for three species: $R$. lineatus (Pers.) Ryv, $R$. ulmarius (Sow. ex Fr.) Imazeki and $R$. umbonatipes Rajch. The latter is a new citation for Brazil. The genus Flaviporus is also represented for three species: $R$. subhydrophilus (Speg.) Rajch. \& Wright, F. venustus David \& Rajch. and Flaviporus sp. Keys for identification, descriptions, remarks and ilustrations of each species are presented.
\end{abstract}

Key words: Rigidoporus, Flaviporus, Systematics. Basidiomycetes. 


\section{Introdução}

Durante o trabalho de levantamento dos Aphyllophorales poliporóides da mata de Araucaria do Parque Nacional de Aparados da Serra, Rio Grande do Sul, determinadas coletas chamaram nossa atenção, já que, segundo as características macroscópicas, tratariam-se de espécies do gênero Rigidoporus Murr. Este gênero xilófago estaria muito bem representado em nossa área de estudo, tanto em araucárias vivas como em latifoliadas mortas.

Foi necessária, no entanto, uma análise microscópica detalhada para separar os representantes do gênero Rigidoporus de outro muito afim, o gênero Flaviporus Murr. Estes dois gêneros diferenciam-se principalmente pelas hifas generativas, que são fibuladas em Flaviporus e apresentam septos simples em Rigidoporus e pela forma dos esporos.

Segundo WRIGHT \& DESCHAMPS (1975), o gênero Rigidoporus é cosmopolita, tendo representantes nas regiões tropicais, sub-tropicais, temperadas e frias, mas com algumas espécies restritas a determinadas regiões. Trata-se de um gênero amplamente conhecido, tendo sido citado para os Estados Unidos (OVERHOLTS, 1953 e GILBERTSON \& RYVARDEN, 1987), Europa (RYVARDEN, 1978), África (RYVARDEN \& JOHANSEN, 1980) e América do Sul (WRIGHT \& DESCHAMPS, 1975 E RAJCHENBERG, 1984). O gênero Flaviporus, no entanto, tem representantes predominantemente tropicais, segundo GINNS (1980).

Faz-se necessário maior estudo destes organismos no intuito de contribuir para o conhecimento, principalmente do gênero Flaviporus, das nossa regiões tropicais e sub-tropicais.

\section{Material e Métodos}

Foram realizadas viagens ao Parque Nacional de Aparados da Serra - RS, para coleta de material. Estas foram realizadas durante três anos, em todas as estaçōes do ano e em diversos locais com mata de Araucaria do referido parque.

O material coletado foi seco em estufa, registrado e depositado no Herbário ICN do Departamento de Botânica da UFRGS.

Para cada frutificação obtida foram feitas observações macro e microscópicas. A análise macroscópica foi realizada com o auxílio de microscópio estereoscópio. As cores foram descritas de acordo com VILLALOBOS-DOMINGUEZ \& VILLALOBOS (1947). Na análise microscópica utilizou-se microscópio óptico, empregando-se cortes anatômicos à mão livre, tratados com $\mathrm{KOH}$ a $5 \%$ e corados com floxina a $1 \%$. Também foram realizados testes histoquímicos com $\mathrm{KOH}$ e reagente Melzer.

A identificação das espécies foi baseada em DAVID \& RAJCHENBERG (1985), RAJCHENBERG (1987 a,b), RAJCHENBERG \& WRIGHT (1987), RYVARDEN \& JOHANSEN (1980) E WRIGHT \& DESCHAMPS (1975), e confirmada com consulta a especialista. 
Os generos Basidiommycetes...

\section{Resultados}

\section{RIGIDOPORUS Murr.}

Bull. Torrey Bot. Club 32:478, 1905.

Basidiocarpo anual a perene, ressupinado a pileado, coriáceo a duro como osso quando seco, de cor laranja-avermelhado, isabelino ou ocráceo, píleo tomentoso a glabro, geralmente zonado, superfície dos poros da mesma cor, em algumas espécies ficando cinza a quase preta ao secar. Contexto denso e fibroso. Sistema hifal monomítico a aparentemente dimítico, hifas generativas com septos simples, variáveis em largura e com paredes engrossadas, em algumas espécies esqueletal ou fortemente esclerificada; hifas generativas de paredes engrossadas a sólidas, sem septos, presentes. Cistídios incrustados presentes ou ausentes. Cistidíolos lisos, presentes entre os basídios na maioria das espécies. Esporos ovóides a globosos, de paredes finas e inamilóides. Causa a podridão branca.

Habitat: sobre decíduas, raramente em madeira de coníferas.

Distribuição: gênero cosmopolita.

Espécie tipo: Polyporus micromegas Mont. - um sinônimo de Rigidoporus microporus (Fr.) Overeem.

\section{Chave para as espécies}

1 - Frutificações presas ao substrato por um umbo diferenciado, ou por uma base afilada, que apresenta uma formação volviforme cobrindo parcialmente o himênio.................... $R$. umbonatipes

1' - Frutificações efuso-reflexas e dimidiadas ..............2

2 - Frutificações grandes, maiores do que $15,0 \mathrm{~cm}$ de largura e em torno de $50,0 \mathrm{~cm}$ de comprimento, de cor creme. Cistídeos ausentes....2.R. ulmarius

2' - Frutificações menores, de cor alaranjada, zonadas concentricamente.

Cistídios de paredes engrossadas presentes .. 1 . $R$. lineatus

\section{Rigidoporus lineatus (Pers.) Ryv.}

Norw. J. Bot. 19: 236. 1972 - Polyporus lineatus Pers., in Gaudichaud, Voyage aut. de Monde p. 174, 1827 - Polyporus zonalis Berk., Ann. Mag. Nat. Hist. 10: 375. 1843.

Basidiocarpo anual, pileado, solitário a imbricado, efuso-reflexo a dimidiado, com 2,5-6,5 x 1,5-3,0 cm e 2,0-7,0 mm de espessura. Carnoso quando fresco, tornando-se muito duro ao secar. Superfície do pileo glabra, zonada e sulcada concentricamente, de cor laranja (DOS $15-12^{\circ}$ ), com zonas em tons de marrom-claro $\left(\mathrm{O} 13-4^{\circ}\right)$ a escuro (DOS $\left.7-7^{\circ}\right)$. Margem definida, inteira, recurvada para baixo, com até $1,5 \mathrm{~mm}$ de largura, da mesma cor da superfície dos 
poros. Himenóforo de cor bege (DOS $16-9^{\circ}$ ). Poros redondos a angulares, 8-9 por $\mathrm{mm}$, tubos inteiros, com até $4,0 \mathrm{~mm}$ de profundidade. Contexto homogêneo, fibroso radialmente, de cor branca a creme $\left(\mathrm{O} 17-7^{\circ}\right)$, com até $4,0 \mathrm{~mm}$ de espessura.

Sistema hifal monomítico. Hifas generativas com septos simples, de paredes finas a engrossadas, com 3,1-5,8 $\mu \mathrm{m}$ de diâmetro, de hialinas a amarelo-ouro. Cistídios presentes na trama, embebidos ou projetando-se acima do himênio, do tipo metulóide, de paredes engrossadas, incrustadas apicalmente ou lisos.

Himênio formado por basidíolos subglobosos. Basídios não observados. Cristiodiolos pontudos, lisos de paredes finas, presentes entre os basidíolos. Esporos subglobosos a globosos, apiculados, frequentemente com uma gota de óleo, com 3,9-5,8 x 4,4-6,0 $\mu \mathrm{m}$, de paredes finas, hialinos e inamilóides (fig.1).

Habitat: sobre troncos mortos de angiospermas indeterminadas.

Distribuição: largamente distribuída nas zonas subtropicais e tropicais. Citada para Ásia, África e Américas.

Material examinado: BRASIL, Rio Grande do Sul, CAMBARÁ DO SUL, Itaimbezinho, 08 V 1987, R. M. SILVEIRA \& R. T. GUERRERO 011 (ICN 56959).

Observações: As frutificações alaranjadas, carnosas, caracterizam macroscopicamente esta espécie. Os cistídios metulóides, incrustados apicalmente ou não, são a principal característica microscópica.

Apesar de ser uma espécie comum no Rio Grande do Sul, foi encontrada apenas uma vez no local de coleta.

\section{Rigidoporus ulmarius (Sow. ex Fr.) Imazeki.}

Bull. Govt. Exp. Sta. Meguro 57: 119. 1952. - Polyphorus ulmarius Sow. ex Fr., Syst. Mycol. 1: 365. 1821. - Fomes geotropus Cooke., Grevillea 13: 119. 1885.

Basidiocarpo perene, pileado, efuso-reflexo a aplạnado, com até 70,0 x $30,0 \mathrm{~cm}$ e $10,0 \mathrm{~cm}$ de espessura. Corticoso quando fresco, tornando-se muito duro, lenhoso ao secar. Superfície do píleo glabra, lisa a rugosa, azonada, de cor esbranquiçada (DOY $\left.18-4^{\circ}\right)$ a creme $\left(\mathrm{O} 17-3^{\circ}\right)$. Margem definida, inteira, lisa, levemente recurvada para baixo, quando seca, com até $1,0 \mathrm{~cm}$ de zona estéril, da mesma cor que a superfície dos poros. Himenóforo de cor alaranjada $(\mathrm{O}$ $15-6^{\circ}$. Poros redondos a angulares, $4-8$ por $\mathrm{mm}$, tubos estratificados, com até $1,0 \mathrm{~cm}$ de longitude. Contexto homogêneo, corticoso, de cor branca a creme (DOY $16-6^{\circ 0}$, com até $9,0 \mathrm{~cm}$ de espessura.

Sistema hifal monomítico. Hifas generativas com septos simples, de paredes finas a engrossadas, com 2,5-6,1 $\mu \mathrm{m}$ de diâmetro, hialinas a amarelo-ouro. Cistídios ausentes.

Himênio, formado por basídios clavados, tetrasporados. Cistidíolos bulbosos, apiculados, lisos de paredes finas, estão presentes entre os basídios. Es- 
poros subglobosos a globosos, frequentemente com uma gota de óleo, com 5,6-7,7 x 4,1-7,0 $\mu \mathrm{m}$, de paredes finas a levemente engrossadas, hialinos a amarelados, inamilóides (fig. 2).

Habitat: sobre Araucaria angustifolia viva.

Distribuição: cosmopolita. Citada para Europa, Ásia, África e Américas.

Material examinado: BRASIL, Rio Grande do Sul, CAMBARÁ DO SUL, Itaimbezinho, 08.V.1987, R.M. Silveira \& R.T. Guerrero 018 (ICN 56962); 01.V.1988, R.M. Silveira \& R.T. Guerrero 077 (INC 56966); 30.IV.1989, R.M. Silveira \& R.T. Guerrero 211 (ICN 56976); 09.XII.1989, R.M. Silveira \& R.T. Guerrero 253 (ICN 80528).

Material adicional examinado: BRASIL, Rio Grande do Sul, PORTO ALEGRE, Parque Farroupilha, V.1987, R.M. Silveira 026 (ICN 56963); TAQUARA, Rolante, Cascata do Chuvisqueiro, 01.XI.1987, R.M. Silveira 027 (ICN 56964); GRAMADO, Araucária Centenária, 10.XI.1987, R.M. Silveira 028 (ICN 56965); ESMERALDA, Est. Ecol. de Aracuri, 29.XI.1988, R.M. Silveira \& F.A. SILVA F $^{0} 160$ (ICN 56967).

Observações: As frutificações perenes, grandes, de cor creme, muitas vezes encontradas sobre árvores vivas, caracterizam macroscopicamente esta espécie. Microscopicamente é caracterizada pelos esporos globosos, grandes, que podem apresentar uma gota de óleo em seu interior, e pelos cistidíolos.

Esta espécie apresenta ocorrência ocasional no local de coleta, tendo sido encontrada apenas sobre Araucária viva.

3. Rigidoporus umbonatipes Rajch.

Mycotaxon 28(1): 116. 1987.

Basiodiocarpo anual, pileado, flabeliforme a cupuliforme, preso ao substrato por um umbo diferenciado ou por uma base afilada, que apresenta uma formação volviforme cobrindo parcialmente o himênio, com 0,5-3,5 $x$ $0,7-2,7 \mathrm{~cm}$ e $0,5-3,0 \mathrm{~mm}$ de espessura, quando cupuliforme, com até $1,5 \mathrm{~cm}$ de altura. De consistência quebradiça a muito dura, como osso, quando seco. Superfície do píleo glabra a levemente tomentosa, zonada concentricamente, de cor bege $\left(\mathrm{O} 16-7^{\circ}\right)$ a marrom-escuro (O 2-3 ${ }^{\circ}$, com zonas em tons de marrom. Margem definida, inteira a recortada, incurvada quando seca, com até 3,0 mm de zona estéril, um pouco mais escura que a superfície dos poros. Himenóforo de cor alaranjada $\left(\mathrm{O} 15-7^{\circ}\right)$ a acinzentada (DOS 12-3 $)$. Poros redondos a angulares, 5-10 por $\mathrm{mm}$, tubos rasos, com até $1,0 \mathrm{~mm}$ de profundidade. Contexto homogêneo, fibroso, de cor creme $\left(\mathrm{O} 15-5^{\circ}\right.$, com até 4,0mm de espessura.

Sistema hifal monomítico. Hifas generativas com septos simples, de paredes finas a engrossadas, com 2,5-7,1 $\mu \mathrm{m}$ de diâmetro, hialinas. Cistidios ausentes. 
Himênio formado por basídios clavados, tetrasporados. Cistidíolos mamiformes, lisos, de paredes finas, presentes entre os basídios. Esporos globosos a subglobosos, apiculados, frequentemente com uma gota de óleo, com 3,0-4,5 x 2,6-4,0 um, de paredes finas, hialinos e inamiloides (Fig.3).

Habitat sobre troncos mortos de angiospermas indeterminadas.

Distribuição: citada para Argentina e Brasil.

Material examinado: BRASIL, Rio Grande do Sul, CAMBARÁ DO SUL, Itaimbezinho, 08.V.1987, R.M. Silveira \& R.T. Guerrero 015 (ICN 56960); 01.V.1988, R.M. Silveira \& R.T. Guerrero 076 (ICN 56961); 30.IV.1989, R.M. Silveira \& R.T. Guerrero 189 (ICN 56968); R.M. Silveira \& R.T. Guerrero 217 (ICN 56970); R.M. Silveira \& R.T. Guerrero 220 (ICN 56971); R.M. Silveira \& R.T. Guerrero 228 (ICN 56972); R.M. Silveira \& R.T. Guerrero 230 (ICN 56974); R.M. Silveira \& R.T. Guerrero 196 (ICN 80513).

Observaçôes: A presença de umbo característico, que prende a frutificação ao substrato, identifica macroscopicamente esta espécie. A cor das frutificações é bastante variável, podendo apresentar-se de alaranjado-claro a um tom cinza-escuro, quase preto.

Esta espécie foi coletada anteriormente na Argentina, tendo sido descrita por RAJCHENBERG (1978a).

A espécie é abundante na região estudada, tendo sido coletada em maior quantidade no outono.

\section{FLAVIPORUS Murr.}

Bull. Torrey Bot. Club 32: 360. 1905.

Basidiocarpo anual, ressupinado a pileado, séssil a lateralmente sub-estipitado, efuso-reflexo ou dimidiado a flabeliforme, pequeno e fino. Himenóforo tipicamente de cor amarela a creme ou rosa-carne, poros pequenos, 6-20 por $\mathrm{mm}$, com até $2,5 \mathrm{~mm}$ de profundidade, de paredes finas, cerosos-duros. Contexto quando fresco aguado carnoso, quando seco rígido, lenhoso a consistência de osso, fino, com ate $1,5 \mathrm{~mm}$ de espessura. Sistema hifal dimítico, hifas tipicamente aglutinadas. Hifas generativas com fíbulas e septos simples, de paredes finas a engrossadas, hialinas. Hifas esqueletais sem septos ou com raros septos simples, de paredes grossas, em algumas espécies ocasionalmente ramificadas. Cistídios presentes na trama, em algumas espécies. Basídios clavados. Esporos subglobosos, largamente oblongos a largamente elipsóides, adaxialmente achatados a levemente côncavos.

Habitat: sobre madeira.

Distribuição: as espécies ocorrem geralmente nos trópicos e hemisfério sul, mas Flaviporus brownei extende-se até a Europa.

Espécie tipo: Polyporus rufoflavus Berk \& Curt., um sinônimo de Flaviporus brownei (Pers.) Donk. 
Os generos Basidiommycetes...

Observações: O gênero Flaviporus foi citado pela primeria vez para o Rio Grande do Sul por RAJCHENBERG (1987b). Este autor estudou os tipos do Padre J. Rick, depositados no Herbário PACA, e publicou Flaviporus subhydrophilus, baseado numa coleta feita por este em 1940, no município de São Leopoldo.

\section{Chave para as espécies:}

1. Frutificações flabeliformes a reniformes. Superfície do píleo zonada, em tons alaranjados a marrom-claro. Sistema hifal dimítico. Esporos cilíndricos a

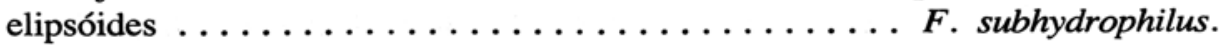

1'. Frutificações dimidadas. Sistema hifal monomítico. Esporos subglobosos

2. Píleo cor-de -rosa pálido, translúcido quando fresco, tornando-se amarronzado e muito duro ao secar. Cistídios ausentes ........... venustus.

2'. Píleo de cor branca a creme, com aspecto de cera, muito quebradiço quando fresco, tornando-se escuro, com zonas de marrom-claro a quase preto, e muito duro ao secar. Cistídios fortemente corads com floxina, projetando-se no himê-

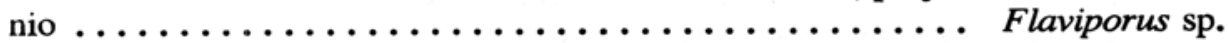

Flaviporus subhydrophilus (Speg.) Rajch \& Wright

Mycologia 79(2): 259. 1987. - Polystictus subhydrophilus Speg., Bot. Acad. Nac. Cienc. Córdoba 11: 444. 1889.

Basidiocarpo anual, pileado, solitário a imbricado, efuso-reflexo, flabeliforme ou reniforme, com 1,9-4,8 x 1,4-3,0cm e 3,0 mm de espessura. Carnoso e flexível quando fresco, tornando-se rígido quase lenhoso ao secar. Superfície do píleo glabra a velutinosa, zonada concentricamente com bandas alaranjadas $\left(\mathrm{OOS} 50-7^{\circ}\right.$ a $\mathrm{O} 16-8^{\circ}$ ) a marrom-claro $\left(\mathrm{O} 14-6^{\circ}\right)$. Margem inteira, incurvada quando seca, com no máximo $1,0 \mathrm{~mm}$ de zona estéril, velutinosa e da mesma cor ou um pouco mais escura que a superfície dos poros. Himenóforo de cor creme (O $17-7^{\circ}$ ) a branco. Poros redondos a angulares, 10 por $\mathrm{mm}$, tubos inteiros, com 0,5-1,0mm de profundidade. Contexto homogêneo, coriáceo, de cor branca, separado da superfície do píleo por uma linha escura, muito fina, alaranjada a marrom-clara, com 1,0-1,5mm de espessura.

Sistema hifal dimítico. Hifas generativas fibuladas, de paredes finas, às vezes levemente engrossadas, com $2,8-4,1 \mu \mathrm{m}$ de diâmetro, hialinas. Hifas esqueletais de paredes muito engrossadas, lúmem visível ou não, com 3,0-7,4 $\mu \mathrm{m}$ de diâmetro, não-ramificadas. Cistídios ausentes.

Himênio formado por basídios clavados e subglobosos, tetrasporados. Cistidíolos cilíndricos a claviformes, lisos, de paredes finas, presentes entre os basídios. Esporos cilíndricos a elipsóides, com 2,7-3,6 x 1,5-2,1 $\mathrm{mm}$, de paredes 
finas, hialinos e inamilóides (Fig. 4).

Habitat: sobre ramos mortos de angiospermas indeterminadas.

Distribuição: citada para Argentina e Brasil.

Material examinado: BRASIL, Rio Grande do Sul, CAMBARÁ DO SUL, Itaimbezinho, 08.V.1987. R.M. Silveira \& R.T. Guerrero 013 (ICN 56952); 30.IV.1988, R.M. Silveira \& R.T. Guerrero 051 (ICN 56953); 18.XI.1988, R.M. Silveira \& R.T. Guerrero 121 (ICN 56957); 30.IV.1989, R.M. Silveira 204 (ICN 56969); R.M. Silveira \& R.T. Guerrero 229 (ICN 56973).

Material adicional examinado: BRASIL, Rio Grande do Sul, ESMERALDA, Est. Ecol. de Aracuri, 29.IX.1988, R.M. Silveira 098 (ICN 56954); R.M. Silveira 099 (ICN 56955); R.M. Silveira 100. (ICN 56956).

Observações: Esta espécie é reconhecida no campo por suas frutificações alaranjadas, zonadas e himenóforo claro, branco e creme, com poros muito pequenos. Microscopicamente é caracterizada pelos esporos cilindricos e pelo sistema hifal dimítico.

Flaviporus subhydrophilus pode, às vezes, ser confundido com Rigidoporus lineatus (pers.) Ryv., pois as duas espécies apresentam o mesmo aspecto geral. Diferem no entanto, no sistema hifal e esporos, pois $R$. lineatus é monomítico e seus esporos são maiores e subglobosos a globosos.

A espécie está bem representada na área em estudo.

Flaviporus venustus David \& Rajch.

Mycotaxon 22(2): 295. 1985.

Basidiocarpo anual, pileado, solitário ou imbricado, efuso-reflexo a dimidiado, com 7,0-20,0 x 6,0-15,0cm e 1,0-4,0 cm de espessura. Carnoso quando fresco, tornando-se muito duro, com consistência de osso ao secar. Superfície do píleo lisa a levemente rugosa, cerosa, de cor rosa (RS 18-6 $)$ a rosa-pálido (RS $18-4^{\circ}$ ). Margem inteira, geralmente sem zona estéril. Himenóforo de cor rosa-pálido (RS18-4 ${ }^{\circ}$ quando fresco. Poros redondos a angulares, 7-10 por $\mathrm{mm}$, tubos inteiros, com 1,5-2,0 $\mu \mathrm{m}$ de comprimento, quando seco. Contexto carnoso, aguado, translúcido a rosa-pálido (RS $\left.18-4^{\circ}\right)$, em estado fresco, quando seco torna-se creme $\left(O 16-6^{\circ}\right)$ a marrom $\left(O 12-6^{\circ}\right)$ e muito duro, apresentando linhas escuras concêntricas, logo abaixo dos tubos, com 5,0-6,0 $\mathrm{mm}$ de espessura.

Sistema hifal monomítico. Hifas generativas fibuladas, de paredes finas a engrossadas, com 2,0-4,0 $\mu \mathrm{m}$ de diâmetro, muito aglutinadas e difíceis de separar. No contexto apresenta hifas de paredes muito engrossadas, com 3,0-6,0 $\mu \mathrm{m}$ de diâmetro, imersas em uma substância aglutinante. Vesículas em forma de clava são encontradas nos dissepimentos. Cistidios ausentes.

Himênio formado por basídios clavados, tetrasporados, com 16,0-24,0 x 4,0-5,5 $\mu \mathrm{m}$. Esporos subglobosos, com 3,6-4,7 x 2,7-3,4 $\mu \mathrm{m}$, de paredes finas, hialinos e inamiloides (Fig. 5). 
Habitat: sobre troncos mortos de angiospermas indeterminadas. Foi observado um exemplar crescendo sobre uma leguminosa viva (Mimosa scabrella).

Distribuição: Conhecida para Antilhas (Martinique) e Brasil.

Material examinado: BRASIL, Rio Grande do Sul, CAMBARÁ DO SUL, Itaimbezinho, 08.V.1987, R.M. Silveira \& R.T. Guerrero 022(ICN 56945); 15.VII.1988, R.M. Silveira \& R.T. Guerrero 080 (ICN 56946); R.M. Silveira \& R.T. Guerrero 082 (ICN 56947); R.M. Silveira \& R.T. Guerrero 083 (ICN 56948); R.M. Silveira \& R.T. Guerrero 085 (ICN 56949); 01.V.1989, R.M. Silveira \& R.T. Guerreo 234 (ICN 56975).

Observações: Esta espécie é abundante na área e chama a atenção por suas frutificações de cor rosa, translúcidas e carnosas, quando jovens e em condições frescas. As frutificações velhas adquirem um tom bege e tornam-se quebradiças. Quando secas modificam muito o seu aspecto, tornando-se duras como osso e de cor marrom.

Quando observado microscopicamente, o contexto apresenta hifas que estão imersas em uma substância aglutinante, o que torna difícil a interpretação do sistema hifal, quando se analisa frutificações secas. Em material fresco, no entanto, pode-se verificar que o contexto é monomítico, apresentando hifas generativas de paredes que podem ser muito engrossadas, porém as fíbulas são bem visíveis.

Flaviporus venustus foi pela primeira vez citada para o Brasil por SILVEIRA \& GUERRERO (1988). O tipo desta espécie é da Guiana Francesa e foi descrito por DAVID \& RAJCHENBERG (1985).

\section{Flaviporus sp.}

Basidiocarpo anual, pileado, efuso-reflexo, dimidiado, às vezes sub-estipitado, com 3,5-5,6 x 1,4-4,5cm e até 6,0 $\mathrm{mm}$ de espessura. Quebradiço, com aspecto de cera quando fresco, tornando-se muito duro, com consistência de osso ao secar. Superfície do píleo glabra, de cor branca a creme (DOY 16-4), tornando-se escuro quando seco, com zonas que variam de marrom-claro (DOS $11-5^{\circ}$ ) a quase preto (DOS $41^{\circ}$ ). Margem inteira a lobada, com até $1,0 \mathrm{~mm}$ de zona estéril, da mesma cor ou geralmente mais escura que a superfície dos poros. Himenóforo de cor branca a creme (DOY 18-4 ${ }^{\circ}$ ) tornando-se bege (DOS $13-4^{\circ}$ ) quando seco. Poros redondos a angulares, (5)8-10 por mm, tubos inteiros, com até $2,0 \mathrm{~mm}$ de profundidade. Contexto homogêneo, compacto a fibroso, duro, de cor creme (DOS $17-7^{\circ}$ ) a marrom-claro (DOS $15-7^{\circ}$ ), podendo, apresentar linhas concêntricas de cor marrom a quase preto, com até 4,0mm de espessura, quando seco.

Sistema hifal monomítico. Hifas generativas fibuladas, de paredes finas a engrossadas, com $2,1-4,8 \mu \mathrm{m}$ de diâmetro, as fíbulas são muito difíceis de visualizar. Cistídios ventricosos a bulbosos, de paredes finas a engrossadas, embebidas ou projetando-se no himênio, fortemente corados com floxina, com aproximadamente $4,5 \mu \mathrm{m}$ de diâmetro, frequentes. 
Himênio formado por basídios clavados, tetrasporados, com 8,5-11,3 x 3,5-3,6 $\mu \mathrm{m}$. Esporos sobglobosos, com 2,5-3,2 x 1,5-2,0 $\mu \mathrm{m}$, de paredes finais, hialinos e inamilóides (Fig. 6).

Habitat: sobre madeira de angiospermas indeterminadas.

Distribuiçâo: registrada somente para o local de coleta.

Material examinado: BRASIL, Rio Grande do Sul, CAMBARÁ DO SUL, Itaimbezinho, 01.V.1988, R.M. Silveira \& R.T. Guerrero 074 (ICN 56958); 30.IV.1989, R.M. Silveira \& R.T. Guerreiro 205 (ICN 80519); R.M. Silveira \& R.T. Guerrero 218 (ICN 80520).

Observações: A espécie é reconhecida a campo pelo píleo de cor branca a creme e com aspecto de cera, muito quebradiço, quando fresco. Quando seco torna-se muito duro, com consistência de osso e com zonas em tom de marrom-claro a quase preto. Microscopicamente apresenta cistídios, que tornam-se fortemente corados em floxina, nem sempre fáceis de serem observados. Os esporos subglobosos e as hifas imersas em uma substância aglutinante, presentes nesta espécie, são características comuns as espécies do gênero Flaviporus Murr., assim como as hifas generativas fibuladas. As fibulas em Flaviporus $s p$. são, no entanto, difíceis de observar.

Flaviporus sp. poderia tratar-se de uma espécie nova, necessitando uma revisão de outros trabalhos com espécies neotropicais, já que trata-se de um gênero conhecido para esta região segundo RYVARDEN \& JOHANSEN (1980), e a mesma não consta na monografia do gênero apresentada por GINNS (1980).

\section{Conclusōes}

A partir dos resultados obtidos até o momento foi possível registrar a ocorrência de três espécies do gênero Rigidoporus Murr. e de três para o gênero Flaviporus Murr.

Das espécies do gênero Rigidoporus, $R$. lineatus e $R$. ulmarius são comuns no estado do Rio Grande do Sul. Rigidoporus ulbonatipes, no entanto, constitui citação nova para o estado e para o Brasil.

Do gênero Flaviporus, $F$. subhydrophilus e $F$. venustus estão sendo citadas pela segunda vez para o estado e para o Brasil. Flaviporus sp. trata-se de um bom representante do gênero Flaviporus, necessitando porém uma adequada revisão de gêneros afins para confirmar sua validade como espécie nova para a ciência.

\section{Agradecimentos}

Ao Dr. Mario Rajchenberg (Universidade de Buenos Aires, Argentina), pela confirmação das espécies. 


\section{Referências Bibliográficas}

DAVID, A. \& RAJCHENBERG, M. 1985. Pore fungi from French Antilles and Guiana. Mycotaxon 22(2): 285-325

GILBERTSON. R. L. \& RYVARDEN, L. 1987. North American polypores. v.2. Megasporoporia - Wrightoporia. Fungiflora. Oslo. 433-885p.

GINNS. J. 1980. The genus Flaviporus Murr. (Polyporaceae) Can. J. Bot. 58: 1578-1590.

OVERHOLTS, L. O. 1953. The Polyporaceae of the United States, Alaska and Canada. University of Michigan Press, Ann Arbor. 466p.

RAJCHENBERG, M. 1984. Basidiomicetos xilofilos de la región Mesopotámica. Republica Argentina. V. políporos resupinados. Rev. Invest. Agrop., INTA, 19(1): 1-105.

RAJCHENBERG, M. 1987a. New South American polypores. Mycotaxon 28(1): 111-118.

RAJCHENBERG, M. 1987b. Type studies of Polyporaceae (Aphyllophorales) described by J. Rick. Nord. J. Bot. 7(5): 553-568.

RAJCHENBERG, M. \& WRIGHT, J. E. 1987. Type studies of Corticiaceae and Polypoaceae (Aphyllophorales) described by C. Spegazzini. Mycologia 79(2): 246-264.

RYVARDEN, L. 1978 The Polyporaceae of North Europe. v.2. Inonotus-Tyromices. Fungiflora, Oslo. 215-507p.

RYVARDEN, L \& JOHANSEN, I. 1980. A preliminars polypore flora of East Africa. Fungiflora, Oslo. 636p.

SILVEIRA, R. M. B. da \& GUERRERO, R. T. 1988. Aspectos biológicos e anatômicos de Flaviporus venustus (Basidiomycetes). Napaea 6: 31-35.

VILLALOBOS-DOMINGUEZ, C \& VILLALOBOS, J. 1947. Atlas de los colores. Libreria el Ateneo Editorial, Buenos Aires, 38 lâminas.

WRIGHT, J. E. \& DESCHAMPS, J.R. 1975. Basidiomicetos xilófilos de la región mesopotámica. II. Los géneres Daedalea, Fomitopsis. Heteroporus, Laetiporus, Nigroporus, Rigidoporus, Perenniporia y Vanderbylia. Rev. Invest. Agrop. INTA, ser. S. Pat. Veg. 12(3): 197-204. 

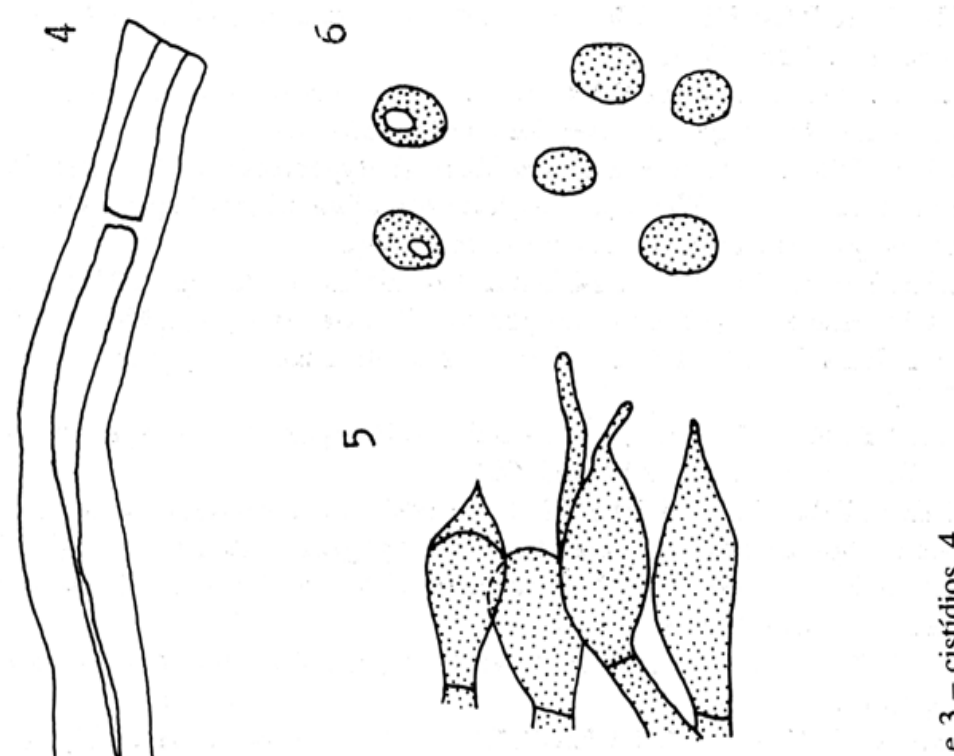

N
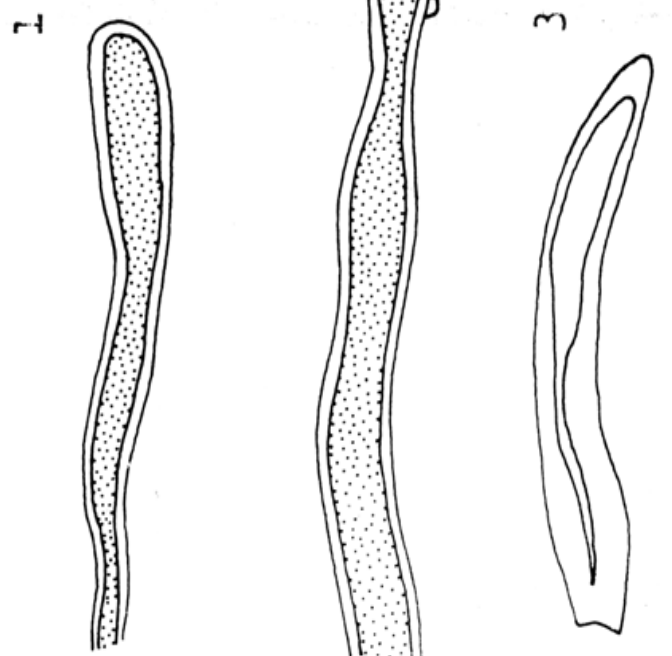

ণ
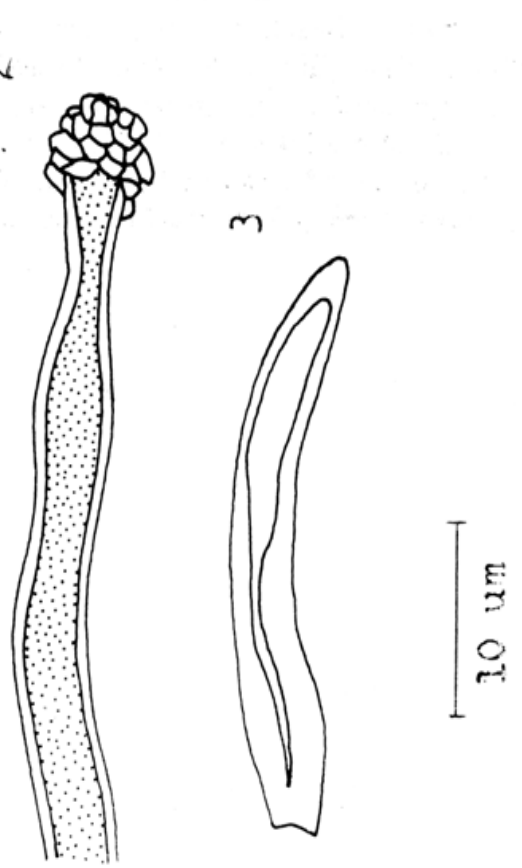

0 is

능

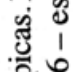

월 음

氶

总芯

خ

它

乞 ํㅡํ

ฐั ฮ

ฐ

ฐับ

ำ

i

氠 


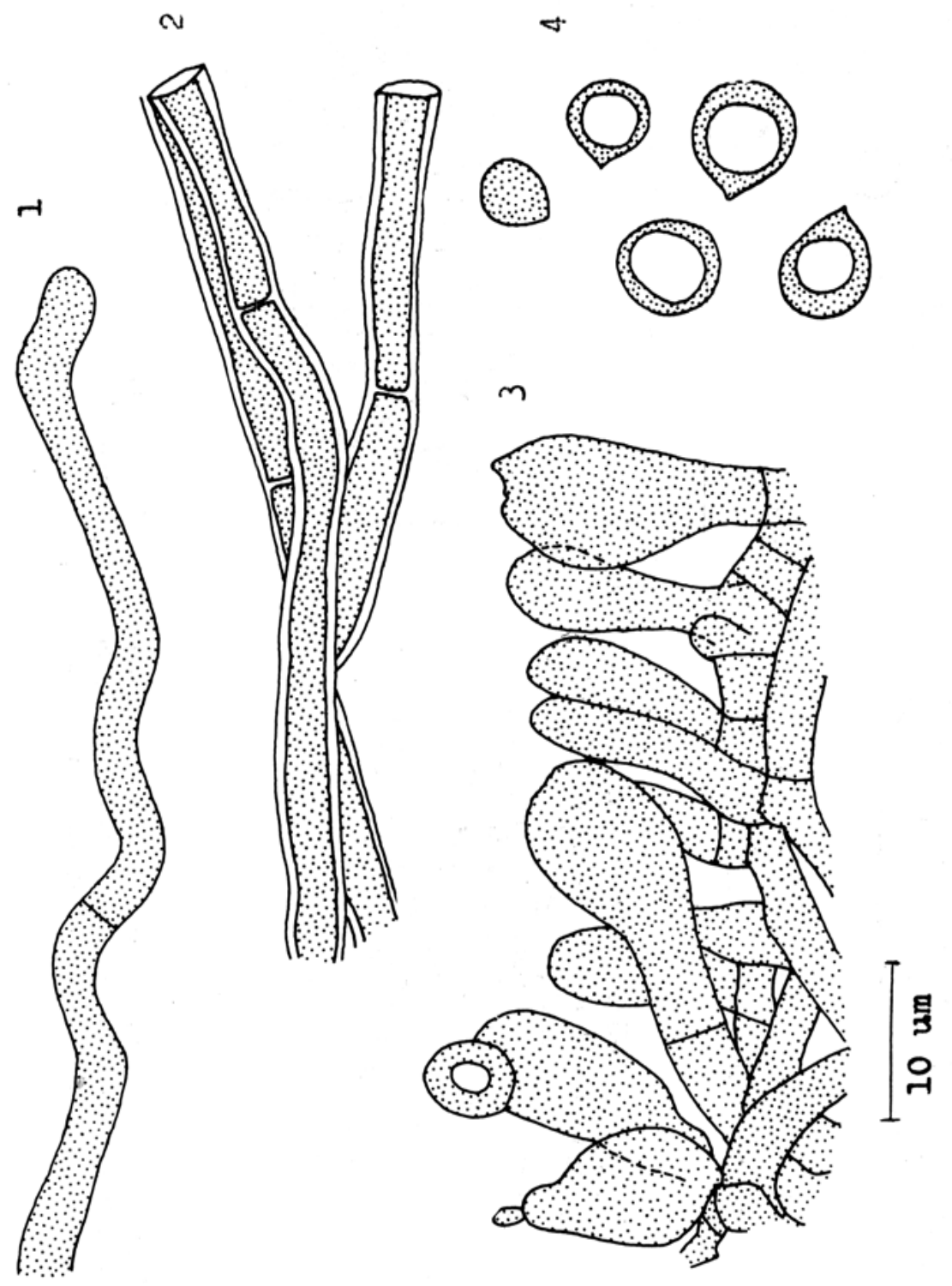

䒯 1

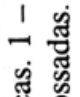

ㅎํㅇ

댕

氙 总

สู เี

光 을

出?

홍

త్

․ㅗ

芒氠

× 1 ․ำ

उั

纪

ษ 엉

녏

일

ำㅇำ

ธิ త్

:

芴 


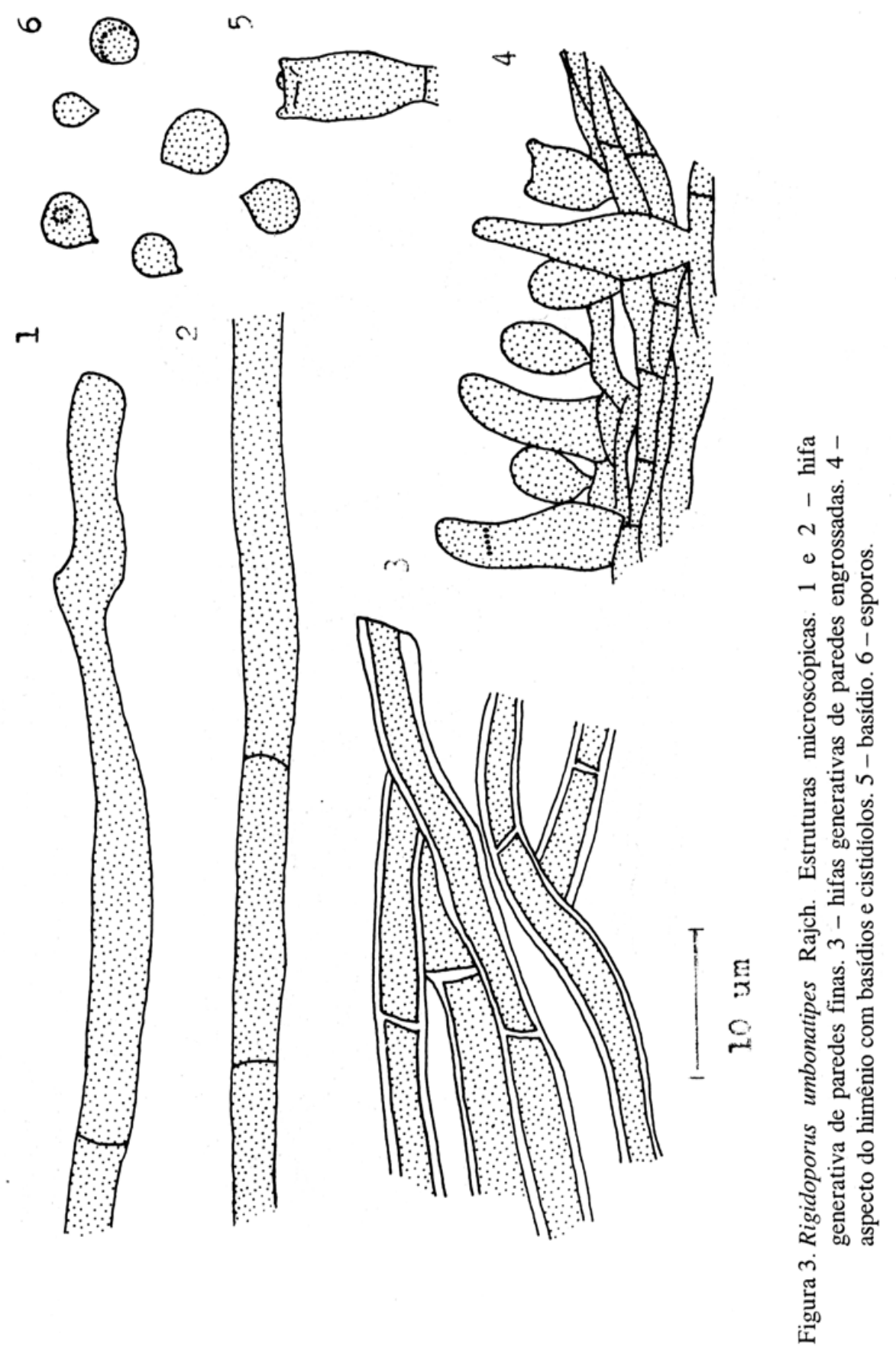




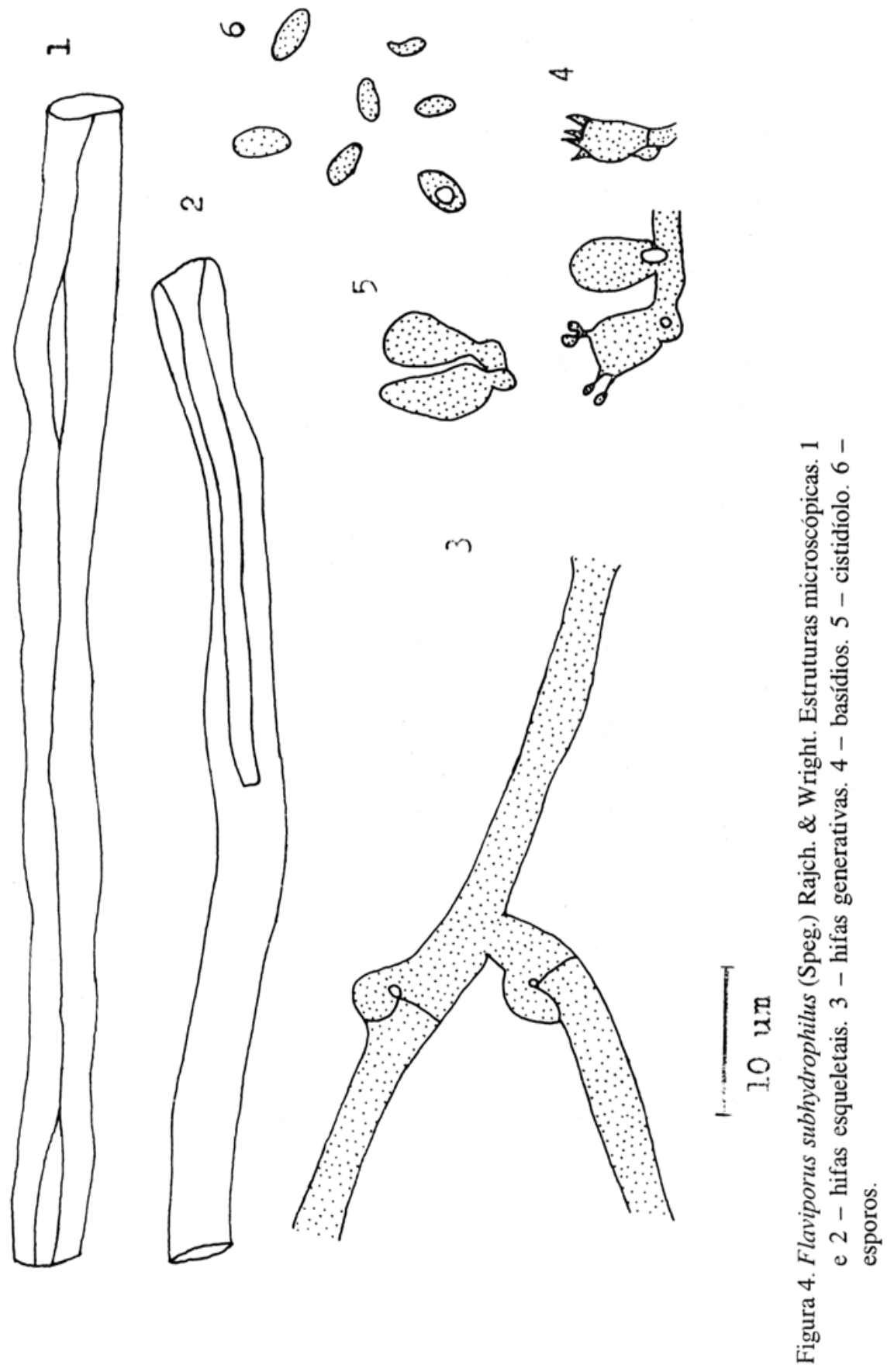




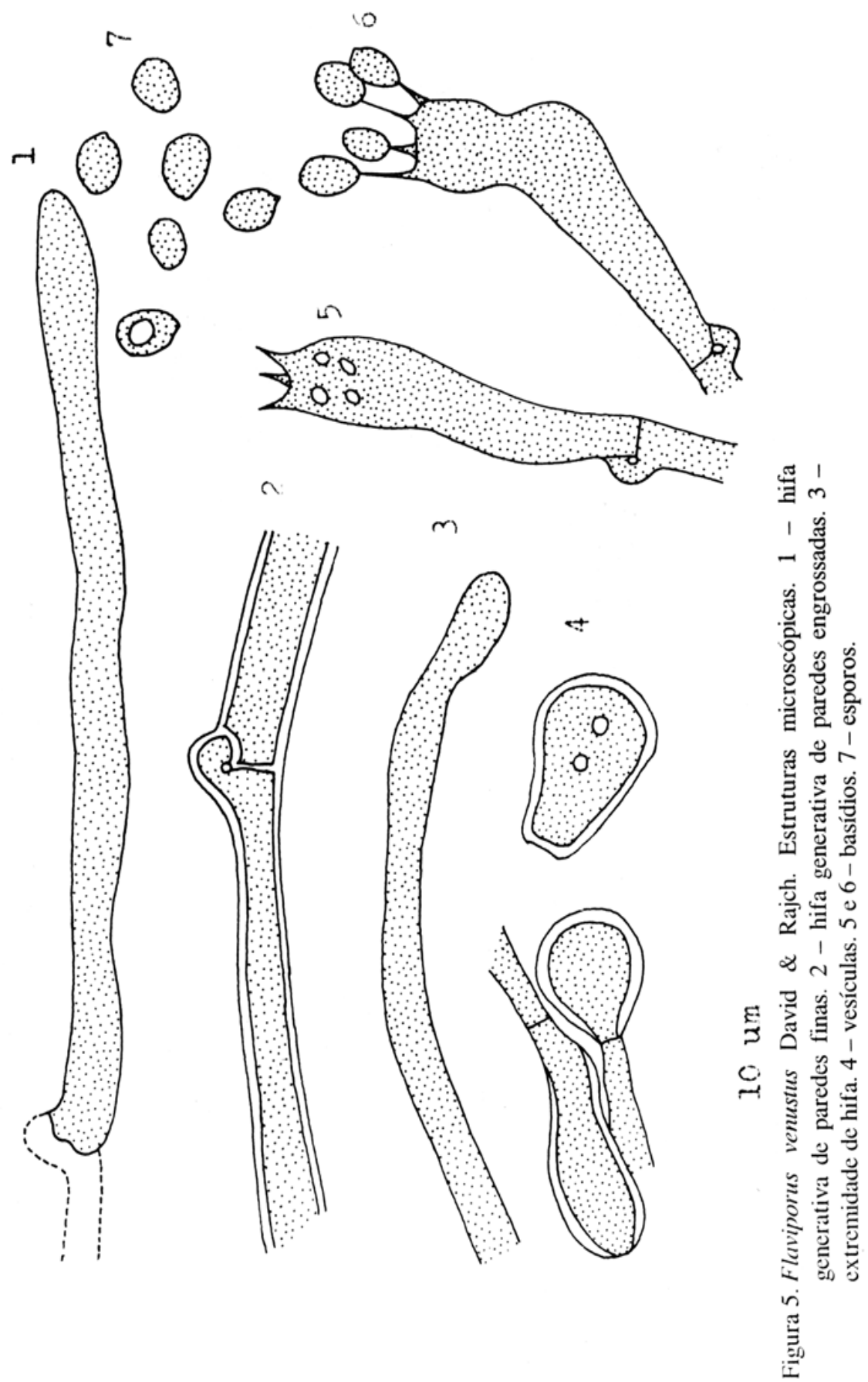



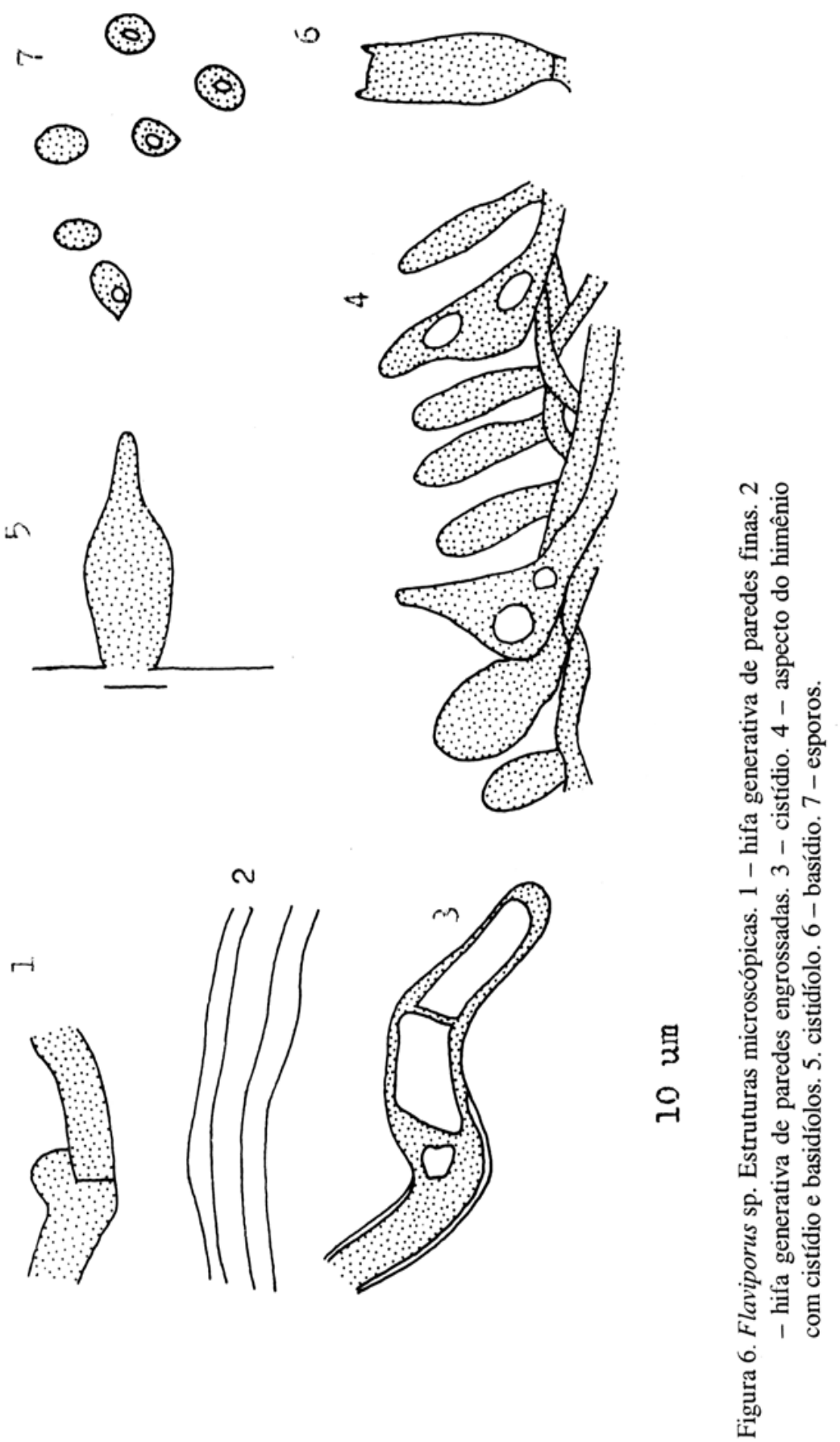